\title{
Injury characteristics and EQ-5D as predictors of personal wellbeing after injury
}

\author{
Susan McAllister · Sarah Derrett · Gabrielle Davie · Rob McGee
}

\begin{abstract}
Objective: A longitudinal study examined the relationships of injury severity, whether the injury was accidental or was caused by an assault, and self-reported EQ-5D soon after injury, with long-term personal wellbeing among participants with a range of injury types and severity.

Methods: Interviews with participants recruited in the Prospective Outcomes of Injury Study (POIS) were conducted up to four time points in the 24 months after injury. Key explanatory variables were New Injury Severity Score (NISS), whether the injury was accidental or resulted from assault, and self-reported health status (five EQ-5D questions and a similar question about cognition) reported at three months. The main outcome measure at 24 months was the Personal Wellbeing Index (PWI) (PWI $<70={ }^{\prime} l^{\prime} w^{\prime}$ wellbeing). Univariate and multivariable analyses examined relationships between explanatory variables and low PWI.
\end{abstract}

Results: Even in a group of people with injuries traditionally regarded as being of mild or moderate anatomical severity, wellbeing continues to be affected for an appreciable time post-injury, with a quarter (27\%) of study participants having a low level of personal wellbeing 24 months after their injury. Neither anatomical injury severity nor hospitalisation were predictive of low personal wellbeing. An increased risk of low personal wellbeing was observed in participants whose injury was caused by an intentional assault (rather than accident), and in those who reported problems three months post-injury with EQ-5D self-care, anxiety/depression or cognitive functioning.

Conclusions: Identification of such individuals early after an injury is of particular importance and ensuring adequate support services are put in place that encourage re-integration back into work and social networks could help prevent on-going poor wellbeing.

Keywords: Injury, personal wellbeing, severity, EQ-5D

\section{Introduction}

Management of injury, particularly in the acute phase, focuses mainly on the physical recovery of the individual with an emphasis on functional outcomes. There may, however, be emotional or psychosocial problems that affect an individual's wellbeing and these in turn can influence recovery and complicate a return to normal functioning and independence. Understanding and identifying ways to predict who might experience long-term low wellbeing is an important component of rehabilitation. Fuhrer (2000) has suggested that evaluations of outcomes of medical rehabilitation are incomplete if they ignore the subjective wellbeing of the individual served. Moreover, it has been stated that patient wellbeing is the primary aim of the transaction between a health care professional and a patient (WHOQOL Group, 1995). 
The severity and type of injury have largely been the focus for investigating outcomes after injury. Most studies include people who have experienced relatively severe anatomical injuries, such as those of participants recruited through hospital or trauma centres. More specifically, many studies have concentrated on people with spinal cord or traumatic brain injury. Interestingly, results from many of these studies have reported better life satisfaction and quality of life than was expected (Albrecht \& Devlieger, 1999; Dijkers, 2004; Jones et al., 2011; Post \& Noreau, 2005). Some explanations for this propose a "response shift" (Dijkers, 2004) or adaptation process (Menzel, Dolan, Richardson, \& Olsen, 2002), whereby people adapt to challenges presented to them by changing their internal standard of expectations. There may also be a sense of surviving a major life event from which one can learn (Albrecht \& Devlieger, 1999). Furthermore, services and supports surrounding a severely injured individual can provide much-needed practical, psychological and social support that can impact on wellbeing (Jones et al., 2011). If such support is not available, it is likely that anatomical severity will not be the main influence on wellbeing, and that the inability to self-care, participate in usual activities, or maintain social networks and social functioning may be more important (Dijkers, 2004; Fuhrer, 2000; Post \& Noreau, 2005).

It has also been noted that the often-used Injury Severity Score was initially developed to predict mortality (Stevenson, Segui-Gomez, Lescohier, Di Scala, \& McDonald-Smith, 2001) rather than disability or wellbeing and that once a patient has survived, physical limitation or psychological factors could be more important for quality of life than the severity of injury or injured body region (van Delft-Schreurs et al., 2014). The EQ-5D (Brooks, 1996) is a generic instrument to describe health status in individuals over a wide range of different illnesses and conditions and has been recommended for use in injury outcome studies (Van Beeck et al., 2007). It is a measure that is able to capture physical, mental and social functioning and is simple to use. Anatomical severity or type of injury alone may not be adequate predictors of wellbeing outcome. A self-reported health status measure such as the EQ-5D might be a more accurate instrument to predict wellbeing outcomes because it seeks to identify the patient's own perception of her or his general health status following injury. The few studies that have used the EQ-5D reported anxiety/depression (Dolan \& Metcalfe, 2012) and pain (Graham, Higuera \& Lora, 2011) as having a much greater impact on subjective wellbeing or life satisfaction than other problems such as poor mobility.

The ability, early after an injury, to identify individuals who have greater susceptibility to poor wellbeing in the long term would allow health care providers and others working closely with injured individuals to target support services and care. In the present longitudinal study, we examine the relationships of injury severity, whether the injury was accidental or was caused by an assault, and self-reported EQ-5D status soon after injury, with long-term personal wellbeing among participants with a range of injury types and with varying severity of injury.

\section{Methods}

\subsection{Study sample and recruitment}

The Prospective Outcomes of Injury Study (POIS) is a prospective longitudinal study of 2856 injured people interviewed (postal questionnaires were conducted for a minority) up to four time points in the 24 months since injury (Derrett et al., 2011). Participants were aged 18-64 years, from one of five regions of New Zealand (NZ) and injured between June 2007 and May 2009. They were recruited from 4881 contactable potential participants (59\% participation rate) identified from the Accident Compensation Corporation's (ACC's) entitlement claimant register. ACC is a 
crown entity and NZ's national no-fault compensation injury insurer. Entitlement claimants have injuries serious enough to potentially require support, such as income compensation (if in paid employment), medical treatment and/or social and rehabilitation services. People with injuries caused by self-harm or sexual assault were excluded from the study. The protocol for this study has been described fully elsewhere (Derrett et al., 2009, 2011).

\subsection{Outcome measure}

The Personal Wellbeing Index (PWI) was used to assess wellbeing 24 months after injury (International Wellbeing Group, 2013). The PWI asks participants how satisfied they are with eight domains of life - standard of living, health, achieving in life, personal relationships, personal safety, feeling part of their community, future security, and spirituality or religion. The rating for each domain is on a scale from 0 (Completely dissatisfied) to 10 (Completely satisfied). Following the International Wellbeing Group Guideline (2013), responses were converted to a 0100 scale, with higher scores indicating greater wellbeing. The eight domain scores were averaged to give a single measure of personal wellbeing between 0 and 100 - the PWI. The normative range for the PWI in western populations is 70-80 (International Wellbeing Group, 2013). Following previous recommendations (Cummins, 2003) the threshold in this paper for defining 'low' wellbeing was a PWI below 70.

A respondent with one, two, or three missing values had a PWI calculated from seven, six, or five domains respectively. If someone had four or more missing values, no PWI was calculated (International Wellbeing Group, 2013). Forty-five individuals (2\%) showed consistently maximum scores in each domain and no individuals had consistently minimum scores. It was decided to include these individuals with consistently maximum scores in the analysis in line with previous research undertaken in the Netherlands (van Beuningen \& de Jonge, 2011).

\subsection{Explanatory variables}

\subsubsection{Injury characteristics}

At the first interview three months after injury, participants were asked if their injury was due to an accident or to intentional assault; and whether, at the time of injury, they felt the injury was a 'threat to their life' or a 'threat of severe longer term disability'.

A New Injury Severity Score (NISS; anatomical injury severity) (Stevenson et al., 2001) was derived for each participant based on clinical diagnosis information provided by ACC. NISS provides an overall measure of anatomical damage due to injury. It is the sum of the squares of an individual's three highest Abbreviated Injury Scale (AIS) scores (or all if fewer than three). Participants were grouped for analysis into three NISS severity categories: 1-3 (least severe; AIS=1 injuries only), 4-6 (middle severity; one AIS=2 injury plus none, one or two AIS=1 injuries) and $>6$ (most severe; at least two AIS $=2$ injuries or one AIS $\geqslant 3$ injury) (Wilson et al., 2013).

Participants were categorised as 'hospitalised' if linkage with the NZ National Minimum Dataset (NMDS) of hospital discharges indicated they had received emergency department treatment for three hours or more, or were admitted to hospital.

\subsubsection{Self-reported health status}

At the three-month interview, questions about health status were asked according to the EQ-5D, which comprises five dimensions - mobility, self-care, usual activities, pain/discomfort, anxiety/depression (Brooks, 1996; The EuroQol Group, 1990). Response options were 'No'; 'Some'; or 'Extreme' problems; the last two were grouped as 'Any problems'. An additional 
question on cognitive functioning was asked in the same format as the EQ-5D questions (Krabbe, Stouthard, Essink-Bot, \& Bonsel, 1999).

"The next statements relate to intellectual activities such as remembering, concentrating, thinking and solving day to day problems"

Participants were also asked at this interview to recall their pre-injury EQ-5D status on the same six dimensions (Wilson, Derrett, Hansen, \& Langley, 2012).

\subsubsection{Other characteristics}

Questions related to age, sex and marital status were taken from the NZ Census (Statistics New Zealand, 2006). People doing paid work were classified as being in paid employment; the remainder were identified as not being in paid employment. Financial status was assessed using a question from the NZ Household Economic Survey (Statistics New Zealand, 2009) that asked people to rate the adequacy of their household income to meet everyday needs such as accommodation, food, clothing and other daily necessities. Responses were given on a four-point scale and grouped as 'More than enough/enough' and 'Just enough/not enough'. A question concerning pre-injury life satisfaction was measured on a five-point scale, 'Completely satisfied' or 'Mostly satisfied', 'Neither satisfied or dissatisfied', 'Mostly dissatisfied, or 'Completely dissatisfied' (the latter three grouped as 'Not satisfied').

A question on participants' social relationships (such as contact with relatives and friends) was asked. Responses from a five-point scale were recorded and grouped as 'Satisfied' ('Completely satisfied' or 'Mostly satisfied') or 'Not satisfied' ('Neither satisfied nor dissatisfied', 'Mostly dissatisfied', or 'Completely dissatisfied').

\subsection{Statistical analysis}

In order to investigate longer term personal wellbeing, data presented in this paper are from participants who completed both the 3-month and 24-month post-injury interviews. Univariate associations between injury characteristics, 3-month EQ-5D and PWI (whether categorised as low or not) were undertaken using chi-squared tests. To investigate possible pre-injury confounding variables, a similar univariate analysis of socio-demographic characteristics, life satisfaction, and pre-injury EQ-5D was also undertaken.

Adjusted relative risks were estimated from multivariable Poisson regression models, with robust standard errors (Zou, 2004). Model 1 examines the relationships between a low PWI and both injury characteristics (NISS, hospitalised, injury cause, threat to life, and threat of longer term disability) and health status (3-month EQ-5D domains and cognitive functioning); Model 2 then adjusted for pre-injury characteristics. P-values and 95\% confidence intervals (CI) were obtained from these models. Analysis was undertaken using Stata 12 (StataCorp, 2011).

\section{Results}

Of the 2856 participants interviewed at three months, 2256 (79\%) completed the 24-month interview, of whom 2239 (99\%) provided complete data on all eight domains of the PWI or had fewer than four missing domain values. The overall PWI mean was 76.2, with the lowest mean score in the domain of 'feeling part of the community' (72.8) and the highest in 'safety' (84.3). Of the 2239, 602 (27\%) had a PWI mean less than 70; and the mean for this 'low' group was 56.8 compared to 83.4 for the remainder of participants.

In the univariate analyses, the variables associated with low PWI at 24 months included age, marital status, pre-injury household income, life satisfaction, social relationships and all pre- 
injury EQ-5D domains and cognitive functioning (Table 1 below), injury cause, threat of longer term disability (Table 2 below), and all of the 3-month EQ-5D domains and cognitive functioning (Table 3 below).

Table 1: Proportion of participants who have 'low' personal wellbeing (PWI) at 24 months according to their pre-injury characteristics

\begin{tabular}{|c|c|c|c|c|}
\hline Pre-injury characteristics & $\begin{array}{c}\text { Total } \\
N^{*}=2239\end{array}$ & $\begin{array}{l}\text { 'Low' PWI } \\
\text { N=602 (\%) }\end{array}$ & $\begin{array}{c}95 \% \\
\text { Confidence } \\
\text { Interval } \\
\end{array}$ & p-value \\
\hline \multicolumn{5}{|l|}{ Gender } \\
\hline Men & 1317 & $362(27.5)$ & 25.1-29.9 & \\
\hline Women & 922 & $240(26.0)$ & 23.2-28.9 & 0.44 \\
\hline \multicolumn{5}{|l|}{ Age } \\
\hline $18-34$ & 699 & $181(25.9)$ & 22.6-29.1 & \\
\hline $35-54$ & 1102 & $334(30.3)$ & $27.6-33.0$ & \\
\hline $55-64$ & 438 & $87(19.9)$ & $16.1-23.6$ & $<0.001$ \\
\hline \multicolumn{5}{|l|}{ Marital status } \\
\hline Single & 463 & $148(32.0)$ & $27.7-36.2$ & \\
\hline Married/living with partner & 1507 & $345(22.9)$ & $20.7-25.0$ & \\
\hline Divorced/separated/widowed & 256 & $105(41.0)$ & $34.9-47.1$ & $<0.001$ \\
\hline \multicolumn{5}{|l|}{ Employment status } \\
\hline Paid employment & 2067 & $549(26.6)$ & $24.6-28.4$ & \\
\hline Not in paid employment & 171 & $53(31.0)$ & $24.0-38.0$ & 0.21 \\
\hline \multicolumn{5}{|l|}{ Household income } \\
\hline Enough & 1458 & $304(20.8)$ & $18.8-22.9$ & \\
\hline Not enough & 759 & $290(38.2)$ & $34.7-41.7$ & $<0.001$ \\
\hline \multicolumn{5}{|l|}{ Social relationships } \\
\hline Satisfied & 2097 & $524(25.0)$ & $(23.1-26.8)$ & \\
\hline Not satisfied & 128 & $71(55.5)$ & $(46.7-64.2)$ & $<0.001$ \\
\hline \multicolumn{5}{|l|}{ Pre-injury life satisfaction } \\
\hline Completely satisfied & 814 & $117(14.4)$ & $11.9-16.8$ & \\
\hline Mostly satisfied & 1256 & $399(31.8)$ & $29.2-34.3$ & \\
\hline Not satisfied & 160 & $82(51.2)$ & $43.4-59.1$ & $<0.001$ \\
\hline \multicolumn{5}{|l|}{ EQ-5D Mobility } \\
\hline No problems & 2096 & $550(26.2)$ & $24.3-28.1$ & \\
\hline Any problems & 139 & $52(37.4)$ & $29.2-45.6$ & 0.004 \\
\hline \multicolumn{5}{|l|}{ EQ-5D Self-care } \\
\hline No problems & 2180 & $580(26.6)$ & $24.7-28.5$ & \\
\hline Any problems & 56 & $22(39.3)$ & $26.1-52.5$ & 0.03 \\
\hline \multicolumn{5}{|l|}{ EQ-5D Usual activities } \\
\hline No problems & 2099 & $545(25.9)$ & $24.1-27.8$ & \\
\hline Any problems & 134 & $56(41.8)$ & $33.3-50.2$ & $<0.001$ \\
\hline \multicolumn{5}{|l|}{ EQ-5D Pain or discomfort } \\
\hline No problems & 1984 & $510(25.7)$ & $23.8-27.6$ & \\
\hline Any problems & 249 & $91(36.5)$ & $30.5-42.6$ & $<0.001$ \\
\hline \multicolumn{5}{|l|}{ EQ-5D Anxiety or depression } \\
\hline No problems & 2101 & $530(25.2)$ & $23.4-27.1$ & \\
\hline Any problems & 131 & $68(51.9)$ & $43.2-60.6$ & $<0.001$ \\
\hline \multicolumn{5}{|l|}{ Cognitive functioning } \\
\hline No problems & 2126 & $543(25.5)$ & 23.7-27.4 & \\
\hline Any problems & 106 & $57(53.8)$ & $44.1-63.4$ & $<0.001$ \\
\hline
\end{tabular}

${ }^{*}$ Missing values are not shown in the table 
Table 2: Proportion of participants who have 'low' personal wellbeing (PWI) at 24 months according to their injury characteristics

\begin{tabular}{|c|c|c|c|c|}
\hline Injury characteristics & $\begin{array}{c}\text { Total } \\
N^{*}=2239\end{array}$ & $\begin{array}{l}\text { ‘Low' PWI } \\
\text { N=602 (\%) }\end{array}$ & $\begin{array}{c}95 \% \\
\text { Confidence } \\
\text { Interval }\end{array}$ & p-value \\
\hline \multicolumn{5}{|l|}{ Injury severity (NISS) } \\
\hline $1-3$ & 882 & $257(29.1)$ & 26.1-32.1 & \\
\hline $4-6$ & 971 & $241(24.8)$ & $22.1-27.5$ & \\
\hline$>6$ & 313 & $87(27.8)$ & $22.8-32.8$ & 0.11 \\
\hline \multicolumn{5}{|l|}{ Hospitalised } \\
\hline No & 1686 & $460(27.3)$ & 25.1-29.4 & \\
\hline Yes & 553 & $142(25.7)$ & $22.0-29.3$ & 0.46 \\
\hline \multicolumn{5}{|l|}{ Injury cause } \\
\hline Accidental & 2162 & $567(26.2)$ & $24.4-28.1$ & \\
\hline Intentional & 73 & $34(46.6)$ & $34.8-58.3$ & $<0.001$ \\
\hline \multicolumn{5}{|l|}{ Threat to life } \\
\hline No & 1952 & $510(26.1)$ & $24.2-28.1$ & \\
\hline Yes/Maybe & 253 & $78(30.8)$ & $25.1-36.6$ & 0.11 \\
\hline \multicolumn{5}{|c|}{ Threat to longer-term disability } \\
\hline No & 1303 & $323(24.8)$ & $22.4-27.1$ & \\
\hline Yes/Maybe & 892 & $258(28.9)$ & $25.9-31.9$ & 0.03 \\
\hline
\end{tabular}

${ }^{*}$ Missing values are not shown in the table

Table 3: Proportion of participants who have 'low' personal wellbeing (PWI) at 24 months according to their EQ-5D and cognitive functioning reported 3 months post-

\begin{tabular}{|c|c|c|c|c|}
\hline \multicolumn{5}{|c|}{ injury } \\
\hline $\begin{array}{l}\text { EQ-5D and cognitive functioning } \\
3 \text { months post-injury }\end{array}$ & $\begin{array}{c}\text { Total } \\
\mathrm{N}^{*}=2239\end{array}$ & $\begin{array}{l}\text { ‘Low' PWI } \\
\text { N=602 (\%) }\end{array}$ & $\begin{array}{c}95 \% \\
\text { Confidence } \\
\text { Interval }\end{array}$ & P-value \\
\hline \multicolumn{5}{|l|}{ EQ-5D Mobility } \\
\hline No problems & 1302 & $312(23.9)$ & $21.6-26.3$ & \\
\hline Any problems & 933 & $290(31.1)$ & $28.1-34.0$ & $<0.001$ \\
\hline \multicolumn{5}{|l|}{ EQ-5D Self-care } \\
\hline No problems & 1715 & $415(24.1)$ & $22.0-26.1$ & \\
\hline Any problems & 521 & $189(36.3)$ & $32.1-40.4$ & $<0.001$ \\
\hline \multicolumn{5}{|l|}{ EQ-5D Usual activities } \\
\hline No problems & 1031 & $212(20.6)$ & $18.1-23.0$ & \\
\hline Any problems & 1202 & $389(32.4)$ & 29.7-35.0 & $<0.001$ \\
\hline \multicolumn{5}{|l|}{ EQ-5D Pain or discomfort } \\
\hline No problems & 672 & $137(20.4)$ & $17.3-23.4$ & \\
\hline Any problems & 1561 & $464(29.7)$ & $27.4-32.0$ & $<0.001$ \\
\hline \multicolumn{5}{|l|}{ EQ-5D Anxiety or depression } \\
\hline No problems & 1744 & $374(21.4)$ & $19.5-23.4$ & \\
\hline Any problems & 488 & $224(45.9)$ & $41.5-50.3$ & $<0.001$ \\
\hline \multicolumn{5}{|l|}{ Cognitive functioning } \\
\hline No problems & 1906 & $446(23.4)$ & $21.5-25.3$ & \\
\hline Any problems & 326 & $154(47.2)$ & $41.8-52.7$ & $<0.001$ \\
\hline
\end{tabular}

${ }^{*}$ Missing values are not shown in the table 
Table 4: Multivariable analysis of injury characteristics, EQ-5D and cognitive functioning measured 3 months post-injury and low personal wellbeing at 24 months

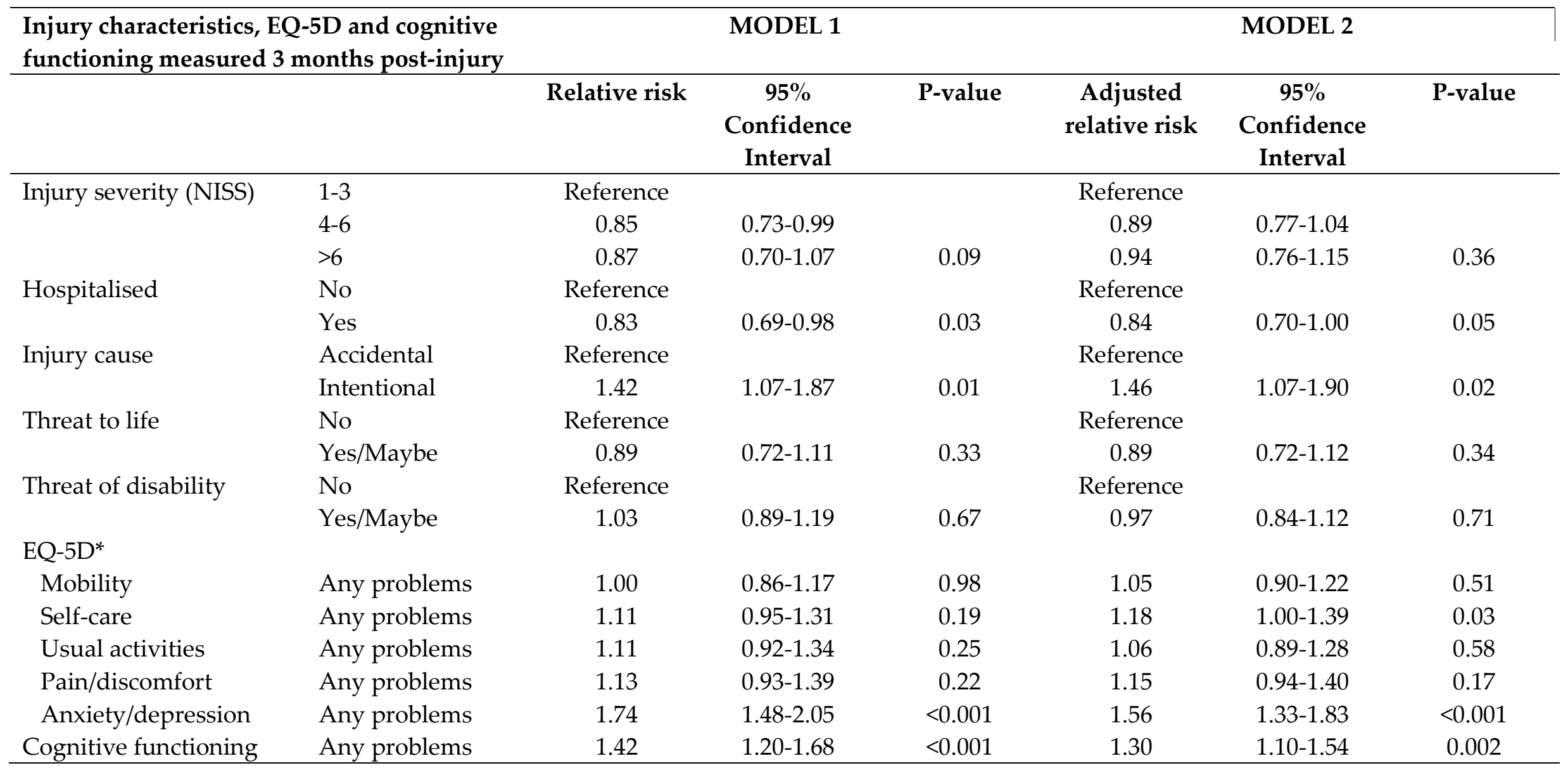

* 'No problems' is the reference category for each of the EQ-5D variables and cognitive functioning

Note: Model 1 adjusted for time from injury to the 3-month interview. Model 2 adjusted for time from injury to the 3-month interview and the following preinjury variables: age, sex, marital status, employment status, household income, social relationships, life satisfaction, EQ-5D and cognitive functioning 
In the first multivariable model of injury characteristics and EQ-5D (Table 4 above), participants whose injury followed an intentional assault were $42 \%$ more likely to have a low PWI after 24 months than those whose injury was accidental. Those who were hospitalised had a significantly lower risk of having a low PWI, as did those who had a NISS score of 4 to 6 (compared to a NISS score of 1 to 3). For EQ-5D, participants who reported problems with anxiety/depression at 3 months were $74 \%$ more likely to have a low PWI after 24 months; those with cognitive functioning problems at 3 months were $42 \%$ more likely to have a low PWI.

After adjustment for pre-injury characteristics (Model 2), injury cause and hospitalisation, 3month EQ-5D anxiety/depression and cognitive functioning remained statistically significant with little change to the relative risks and confidence intervals. The relationship between PWI and NISS was attenuated whereas that between PWI and 3-month EQ-5D self-care was strengthened.

\section{Discussion}

Two years after an injury, about a quarter of study participants experienced a low level of personal wellbeing that was well below the normal range for western populations and also below a 2009 estimate for the European NZ population (Sibley, Harre, Hoverd, \& Houkamau, 2011). There was no evidence to suggest anatomical injury severity (NISS) was predictive of this low level; indeed, higher NISS anatomical injury severity showed a reduced risk of low wellbeing at 24 months. Similarly, participants who were hospitalised, which is associated with severity, also had reduced risk of low wellbeing. An increased risk of low personal wellbeing was observed in participants whose injury was caused by an intentional assault, and in those who reported problems three months post-injury with EQ-5D self-care, anxiety/depression or cognitive functioning.

Injury severity and its influence on wellbeing or life satisfaction has been the subject of much discussion over the years, with studies often showing results contrary to expectations (Albrecht \& Devlieger, 1999; Jones et al., 2011; Post \& Noreau, 2005). Many of these studies have focussed on more serious trauma, such as spinal cord injury. Therefore it was interesting to see in our study of participants encompassing a range of injury types and severity that more severe anatomical injury was not predictive of wellbeing, and that those not hospitalised were more likely to report longer term poor wellbeing. There may be several reasons for this lack of association between injury severity and wellbeing. For example, the severity of anatomical injury (a measure of threat to life) may simply be insufficient as a predictor of wellbeing among those who survive an injury event (van Delft-Schreurs et al., 2014). Elsewhere, we have reported the severity of anatomical injury does not necessarily predict disability burden among survivors of injury events (Derrett et al., 2013; Wilson et al., 2012). A further reason suggested by Jones and colleagues (2011) is that more severely injured individuals receive higher levels of services and support that limit the negative effects of injury severity.

In NZ, people who have an injury receive treatment and rehabilitation support through the ACC. For the seriously injured rehabilitation support can comprise a range of support services that continue as long as they are required. For individuals with less serious injuries support continues for a limited time, after which they will be expected to return to work. It is possible, therefore, that support is discontinued before the individual is fully recovered and she or he may be left to cope with ongoing disability that may be considered minor but that has a negative impact on her or his life and wellbeing. Among the more seriously injured there may also be a sense of relief and appreciation of life and of one's survival after a major life event, a greater sense of learning and growing through a difficult situation and a greater sense of purpose 
(Albrecht \& Devlieger, 1999; Frank, 1997). Individuals with a less serious injury, on the other hand, may have a greater expectation of returning to their 'normal' pre-injured state, and if this does not occur, they may experience significant frustration and hence report poorer wellbeing.

The only injury-specific variable that was statistically significant in both the adjusted and unadjusted multivariable models was whether the injury had been the result of an intentional assault rather than an accident. Adjustment for pre-injury variables should have accounted for any pre-injury social disadvantage contributing to low wellbeing, so the low wellbeing observed at 24 months could be due to the added negative impact of dealing with the legal system, a greater sense of being a 'victim', and an increased chance of post-traumatic stress disorder (Feehan, Nada-Raja, Martin, \& Langley, 2001).

Not surprisingly, those who reported problems with anxiety or depression soon after being injured had a much greater risk of low wellbeing, even after adjusting for pre-injury anxiety/depression and other characteristics. This is consistent with other studies that have reported acute depression to be negatively associated with quality of life, functional outcomes and wellbeing (Graham, Higuera \& Lora, 2011; Holbrook, Anderson, Sieber, Browner, \& Hoyt, 1999; O’Donnell, Creamer, Elliot, Atkin, \& Kossmann, 2005; Zatzick et al., 2008).

People who have difficulties with cognition subsequent to a brain injury have been reported to have poorer quality of life and life satisfaction compared to their peers (Dijkers, 2004). Moreover, Corrigan, Bogner, Mysiw, Clinchot and Fugate (2001) reported that depressed mood, current social integration, employment, and prior history of substance abuse had a greater association with poor life satisfaction two years after a traumatic brain injury than did the cause of injury or functional measures at the time of discharge from rehabilitation.

The absence of a pre-injury measure of personal wellbeing is a limitation of the study. Wellbeing has been described as a state of being fairly stable, held constant by an individual's personality (Headey \& Wearing, 1989; Diener, Suh, Lucas, \& Smith, 1999). In that case, an individual's level of post-injury wellbeing would most likely be similar to that individual's preinjury level and would most likely be minimally affected by the injury itself. Longitudinal studies, however, have shown that life events such as injury do matter, and even though people often adapt, such adaptation is not always rapid or complete (Clark, Diener \& Lucas, 2008; Lucas, 2007). Although we did not have a pre-injury measure of personal wellbeing, we were able to adjust for pre-injury life satisfaction. While this was only a single question, results did show moderately strong correlation with the PWI (0.63). Adjusting for pre-injury life satisfaction did not change the results. While it is possible that consistently reporting minimum or maximum scores in all eight domains of the PWI could indicate the use of response sets, it is also possible that certain individuals could respond at a time when they were very strongly satisfied with life or very strongly dissatisfied. As our dataset included only a small number of people with consistent maximum scores it was decided to keep them in the analysis. Categorising the EQ-5D 'some' and 'extreme' problems responses as 'Any problems' for the analysis may have caused a loss of detail but the number of participants who responded 'extreme' was small, so estimates for this group alone would have been imprecise. A further limitation could be a bias in participants' over-rating their pre-injury health status. However, such bias in our cohort was analysed by Wilson et al. (2012), who reported that although there was over-rating of pre-injury status, this appears to be minimal. Finally, the majority of participants were in paid employment at the time of their injury, therefore findings cannot be generalised to retired populations or to those not in paid employment.

A strength of our study was having pre-injury measures for many of the factors that could potentially confound the relationship between injury severity, EQ-5D and longer term wellbeing. 
Adjustment for these factors did not substantially alter many of the relationships between the key explanatory variables and PWI. Further strengths included having a large cohort of injury participants encompassing a range of injury types and severity; a good follow-up rate, and the inclusion of both hospitalised and non-hospitalised participants. Finally, relatively few participants had missing values on the PWI; and analysis that excluded these people did not result in any meaningful change to the relative risk estimates.

Subjective wellbeing is a complex concept (Dodge, Daly, Huyton, \& Sanders, 2012) influenced by a wide range of factors, both internal, such as an individual's sense of self-esteem, optimism and resilience, and external, such as marital, employment, and financial status (Cummins, 1996; Headey \& Wearing, 1992). The two key messages emerging from this study are, firstly, that even in a somewhat under-researched group of people with injuries, including injuries traditionally regarded as being of mild or moderate anatomical severity, wellbeing continues to be affected for an appreciable time post-injury. Extending support services beyond the time frame normally allocated appears to be warranted to enable this group to return to their work and everyday lives. Secondly, the severity of anatomical injury alone did not predict subsequent low wellbeing and, for the most part, neither did the EQ-5D health status measure. Rather, early identification after an injury of individuals who have problems with anxiety or depression, cognitive functioning, or whose injury was caused by assault is of particular importance. Providing the necessary support, or directing the individual to where such support might be available, and re-integrating them into work and social networks could prevent ongoing poor wellbeing in these people.

\section{Acknowledgments}

We are grateful to all participants in this study. The study was funded by the Health Research Council of New Zealand (2007-2013) and co-funded by the Accident Compensation Corporation, New Zealand (20072010). The views and conclusions expressed herein are the authors' and may not reflect those of the funders. Ethical approval for the study came from the New Zealand Health and Disability Multi-Region Ethics Committee (MEC/07/07/093).

\section{Authors}

Susan McAllister

University of Otago

Sarah Derrett

University of Otago \& Massey University

s.l.derrett@massey.ac.nz

Gabrielle Davie

University of Otago

Rob McGee

University of Otago

\section{Publishing Timeline}

Received 2 June 2014

Accepted 25 July 2014

Published 31 December 2014 


\section{References}

Albrecht, G.L. \& Devlieger, P.J. (1999). The disability paradox: High quality of life against all odds. Social Science \& Medicine, 48, 977-988. http://dx.doi.org/10.1016/S0277-9536(98)00411-0

Brooks, R. (1996). EuroQol: The current state of play. Health Policy, 37, 53-72. http://dx.doi.org/10.1016/0168-8510(96)00822-6

Clark, A., Diener, Y., \& Lucas, R. (2008). Lags and leads in life satisfaction: A test of the baseline hypothesis. The Economic Journal, 118, F222-F243. http://dx.doi.org/10.1111/j.1468-0297.2008.02150.x

Corrigan, J., Bogner, J., Mysiw, W., Clinchot, D., \& Fugate, L. (2001). Life satisfaction after traumatic brain injury. The Journal of Head Trauma Rehabilitation, 16(6), 543-555. http://dx.doi.org/10.1097/00001199-200112000-00003

Cummins, R.A. (2003). Normative life satisfaction: Measurement issues and a homeostatic model. Social Indicators Research, 64, 225-256. http://dx.doi.org/10.1023/A:1024712527648

Cummins, R.A. (1996). The domains of life satisfaction: An attempt to order chaos. Social Indicators Research, 38, 303-328. http://dx.doi.org/10.1007/BF00292050

Derrett, S., Davie, G., Ameratunga, S., Wyeth, E., Colhoun, S., Wilson, S., ... \& Langley, J. (2011). Prospective outcomes of injury study: Recruitment, and participant characteristics, health and disability status. Injury Prevention, 17, 415-418. http://dx.doi.org/10.1136/injuryprev-2011-040044

Derrett, S., Langley, J., Hokowhitu, B., Ameratunga, S., Hansen, P., Davie, G., .. \& Lilley, R. (2009). Prospective outcomes of injury study. Injury Prevention, 15, 351.

Derrett, S., Wilson, S., Samaranayaka, A., Langley, J., Wyeth, E., Ameratunga, S., .. \& Mauiliu, M. (2013). Prevalence and predictors of disability 24 months after injury for hospitalised and non-hospitalised participants: Results from a longitudinal cohort study in New Zealand. PLoS ONE, 8, 1-14. http://dx.doi.org/10.1371/journal.pone.0080194

Diener, E., Suh, E.M., Lucas, R.E. \& Smith H.L. (1999). Subjective well-being: Three decades of progress. Psychological Bulletin, 125, 276-302. http://dx.doi.org/10.1037/0033-2909.125.2.276

Dijkers, M.P. (2004). Quality of life after traumatic brain injury: A review of research approaches and findings. Archives of Physical Medicine and Rehabilitation, 85, 21-35. http://dx.doi.org/10.1016/j.apmr.2003.08.119

Dodge, R., Daly, A., Huyton, J. \& Sanders, L. (2012). The challenge of defining wellbeing. International Journal of Wellbeing, 2, 222-235. http://dx.doi.org/10.5502/ijw.v2i3.4

Dolan, P. \& Metcalfe, R. (2012) Valuing health: A brief report on subjective well-being versus preferences. Medical Decision Making, 32, 578-582. http://dx.doi.org/10.1177/0272989X11435173

Feehan, M., Nada-Raja, S., Martin, J.A. \& Langley, J.D. (2001). The prevalence and correlates of psychological distress following physical and sexual assault in a young adult cohort. Violence and Victims, 16, 49-63.

Frank, A. (1997). Illness as moral occasion: Restoring agency to ill people. Health, 1(2), 131-148.

Fuhrer, M.J. (2000). Subjectifying quality of life as a medical rehabilitation outcome. Disability and Rehabilitation, 22, 481-489. http://dx.doi.org/10.1080/096382800413961

Graham, C., Higuera, L. \& Lora, E. (2011). Which health conditions cause the most unhappiness? Health Economics, 20, 1431-1437. http://dx.doi.org/10.1002/hec.1682

Headey, B. \& Wearing, A. (1989). Personality, life events, and subjective well-being: Toward a dynamic equilibrium model. Journal of Personality and Social Psychology, 57, 731-739. http://dx.doi.org/10.1037/0022-3514.57.4.731

Headey, B. \& Wearing, A. (1992). Subjective well-being: A stocks and flows framework. In: Strack, F., Argyle, M., Schwarz, N., editors. Subjective Wellbeing: An interdisciplinary perspective. Oxford: Pergamon Press. pp. 49-76.

Holbrook, T.L., Anderson, J.P., Sieber, W.J., Browner, D. \& Hoyt, D.B. (1999). Outcome after major trauma: 12-month and 18-month follow-up results from the Trauma Recovery Project. Journal of Trauma, 46, 765-771. http://dx.doi.org/10.1097/00005373-199905000-00003

International Wellbeing Group (2013). Personal Wellbeing Index: 5th Edition. Melbourne: Australian Centre on Quality of Life, Deakin University. [Cited 23 October 2013] http://www.deakin.edu.au/research/acqol/instruments/wellbeing-index/index.php 
Jones, J.M., Haslam, S.A., Jetten, J., Williams, W.H., Morris, R. \& Saroyan, S. (2011). That which doesn't kill us can make us stronger (and more satisfied with life): The contribution of personal and social changes to well-being after acquired brain injury. Psychology and Health, 26, 353-369. http://dx.doi.org/10.1080/08870440903440699

Krabbe, P.F.M., Stouthard, M.E.A., Essink-Bot, M-L. \& Bonsel, G.J. (1999). The effect of adding a cognitive dimension to the EuroQol multi-attribute health-status classification system. Journal of Clinical Epidemiology, 52, 293-301. http://dx.doi.org/10.1016/S0895-4356(98)00163-2

Lucas, R. (2007). Long-term disability is associated with lasting changes in subjective well-being: Evidence from two nationally representative longitudinal studies. Journal of Personality and Social Psychology, 92, 717-330. http://dx.doi.org/10.1037/0022-3514.92.4.717

Menzel, P., Dolan, P., Richardson, J. \& Olsen, J.A. (2002). The role of adaptation to disability and disease in health state valuation: A preliminary normative analysis. Social Science and Medicine, 55, 2149-2158. http://dx.doi.org/10.1016/S0277-9536(01)00358-6

O'Donnell, M.L., Creamer, M., Elliott, P., Atkin, C. \& Kossmann, T. (2005). Determinants of quality of life and role-related disability after injury: Impact of acute psychological responses. Journal of Trauma, 59, 1328-1335. http://dx.doi.org/10.1097/01.ta.0000197621.94561.4e

Post, M. \& Noreau, L. (2005). Quality of life after spinal cord injury. Journal of Neurological Physical Therapy, 29, 139-146. http://dx.doi.org/10.1097/01.NPT.0000282246.08288.67

Sibley, C., Harre, N., Hoverd, W.J. \& Houkamau, C.A. (2011). The gap in the subjective wellbeing of Maori and New Zealand Europeans widened between 2005 and 2009. Social Indicators Research, 104, 103-115. http://dx.doi.org/10.1007/s11205-010-9729-x

StataCorp. (2011). Stata Statistical Software: Release 12. College Station, TX: StataCorp LP.

Statistics New Zealand. (2006). Census 2006: Definitions and Questionnaires [Cited 23 October 2013]. http://www.stats.govt.nz/Census/about-2006-census.aspx

Statistics New Zealand. (2009). Household Economic Survey 2009-10 printable questionnaires [Cited 23 October 2013].

http://www.stats.govt.nz/browse for stats/people and communities/Households/hes-flowcharts2009-10.aspx

Stevenson, M., Segui-Gomez, M., Lescohier, I., Di Scala, C. \& McDonald-Smith, G. (2001). An overview of the injury severity score and the new injury severity score. Injury Prevention, 7, 10-13. http://dx.doi.org/10.1136/ip.7.1.10

The EuroQol Group. (1990). EuroQol - a new facility for the measurement of health-related quality of life. Health Policy, 16, 199-208. http://dx.doi.org/10.1016/0168-8510(90)90421-9

Van Beeck, E., Larsen, C., Lyons, R., Meerding, W-J., Mulder, S. \& Essink-Bot, M-L., (2007). Guidelines for the conduction of follow-up studies measuring injury-related disability. Journal of Trauma, Injury, Infection and Critical Care, 62, 534-550. http://dx.doi.org/10.1097/TA.0b013e31802e70c7

van Beuningen, J. \& de Jonge, T. (2001). The Personal Wellbeing Index. Construct validity for the Netherlands. Den Haag: Centraal Bureau voor de Statistiek. [Cited 23 October 2013] http://www.cbs.nl/NR/rdonlyres/F0C01716-3E08-4A6E-AC30-9234A5EFC5FD/0/2011x1024art.pdf

van Delft-Schreurs, C.C.H.M., van Bergen, J.J.M., de Jongh, M.A.C., van de Sande, P., Verhofstad, M.H.J. \& de Vries, J. (2014). Quality of life in severely injured patients depends on psychosocial factors rather than on severity or type of injury. Injury, 45, 320-326. http://dx.doi.org/10.1016/j.injury.2013.02.025

WHOQOL Group. (1995). The World Health Organization quality of life assessment (WHOQOL): Position paper from the World Health Organisation. Social Science and Medicine, 41, 1403-1409. http://dx.doi.org/10.1016/0277-9536(95)00112-K

Wilson, R., Derrett, S., Hansen, P. \& Langley, J. (2012). Retrospective evaluation versus population norms for the measurement of baseline health status. Health and Quality of Life Outcomes, 10, 68. http://dx.doi.org/10.1186/1477-7525-10-68

Wilson, S., Derrett, S., Cameron, I.D., Samaranayaka, A., Davie, G. \& Langley, J. (2013). Prevalence of poor outcomes soon after injury and their association with the severity of the injury. Injury Prevention, 20, 57-61. http://dx.doi.org/10.1136/injuryprev-2012-040690 
Zatzick, D., Jurkovich, G.J., Rivara, F.P., Wang, J., Fan, M-Y., Joesch, J. \& Mackenzie, E. (2008). A national US study of post traumatic stress disorder, depression, and work and functional outcomes after hospitalization for traumatic injury. Annals of Surgery, 248, 429-437.

Zou, G. (2004). A modified poisson regression approach to prospective studies with binary data. American Journal of Epidemiology, 159, 702-706. http://dx.doi.org/10.1093/aje/kwh090 